\title{
The expression of CXCL13 and its relation to unfavorable clinical characteristics in young breast cancer
}

\author{
Lujia Chen ${ }^{1 \dagger}$, Zhongxi Huang ${ }^{2 \dagger}$, Guangyu Yao ${ }^{1 \dagger}$, Xiaoming Lyu ${ }^{3}$, Jinbang $\mathrm{Li}^{2}$, Xiaolei Hu${ }^{1}$, Yahong Cai ${ }^{1}$, Wenji Li ${ }^{1}$, \\ Xin $\mathrm{Li}^{2^{*}}$ and Changsheng $\mathrm{Ye}^{1 *}$
}

\begin{abstract}
Background: Young breast cancer occupies a higher and higher proportion of breast cancer, especially in Asia, and is associated with a more unfavorable prognosis compared with the disease arising in older women. However, the poor prognosis of young breast cancer cannot be fully explained by the clinical and molecular factors.

Methods: This study investigated 1125 Chinese breast cancer patients diagnosed from 2009 to 2013. A data mining of gene expression profiles was performed for the young and older breast cancer patients, identifying significantly differentially expressed genes. Quantitative RT-PCR, Western blotting and immunohistochemistry assay were carried out for the clinical sample validations.

Results: The investigation firstly displayed that young patients ( $\leq 45$ years) accounted for $47.6 \%$ (535/1125) of breast cancer, and clinically associated with some unfavorable factors related to poor prognosis, such as invasive pathological type, high tumor grade, lymph node positive, ER negative and triple-negative subtype. Subsequently, 553 significantly differentially expressed genes were identified by the data mining. Of them, a set of genes related to immune function were observed to be up-regulated in young patients with breast cancer. Impressively, the CXCL13 (C-X-C motif chemokine 13) expression level showed the most significant difference $\left(F C=2.64, P=8.2 \times 10^{-4}\right)$. Furthermore, the validations with clinical samples and correlation analysis demonstrated that CXCL13 was indeed highly expressed in young breast cancer and closely associated with some prognostic factors including lymph node positive and ER negative.
\end{abstract}

Conclusion: This is the first to indicate the clinical relevance of CXCL13 to young breast cancer and represents a potential therapeutic target for young breast cancer.

\section{Introduction}

Breast cancer is currently one of the most common malignancies and a leading cause of cancer death in women worldwide, accounting for $23 \%$ (1.38 million) of all new cancer cases and $14 \%(458,400)$ of all cancer deaths [1]. It is among American women in 2014 that breast cancer is expected to account for $29 \%(232,670)$ of new cancers, being the highest incidence of women cancer, and

\footnotetext{
*Correspondence: xinli268@gmail.com; yechsh2014@hotmail.com

${ }^{\dagger}$ Equal contributors

${ }^{2}$ Cancer Research Institute and the Provincial Key Laboratory of Functional Proteomics, Southern Medical University, Guangzhou, Guangdong 510515, People's Republic of China

'Breast Center, Nanfang Hospital, Southern Medical University, Guangzhou, Guangdong 510515, People's Republic of China

Full list of author information is available at the end of the article
}

$15 \%(40,000)$ of the total cancer deaths, being second only to lung cancer [2]. Although the incidence and mortality of breast cancer in Asia is lower than that of Western countries, the incidence of young breast cancer is much higher [3-6]; young breast cancer accounts for $10 \%$ to $25 \%[6,7]$ of all female breast cancer in Asia, even $45 \%$ in Saudi Arabia [8]. It is worth noting that breast cancer is a malignant tumor that mainly affects post-menopausal women, but the patients with breast cancer are getting younger and younger in recent years $[4$, 9] and young breast cancer accounts for $14 \%$ of all young malignant tumor [10], and $7 \%$ of all breast cancer [11].

Besides occupying a higher proportion of breast cancer, another reason why we should turn our attention to young breast cancer is its more aggressive biological 
behavior and clinical association with a more unfavorable prognosis compared with the disease arising in older women [12]. Young women with breast cancer tend to have more advanced tumor TNM staging, more invasive pathological type, higher tumor grade, higher lymph node positivity, higher proportion of triple-negativity, higher HER2 expression and lower ER/PR positivity [13-22]. A multivariate analysis [23], including the age at diagnosis, tumor size, lymph node status, tumor grade, year of treatment, protocol allocation, and expected mortality, found that even if multiple impact factors were adjusted, the breast cancer diagnosed at a young age was closely associated with an increased risk of death. Weber-Mangal et al. has observed some specific chromosome aberrations (such as loss of 8p22-p23 and gain of 8q23-q24) in patients with early onset breast cancer using comparative genomic hybridization $(\mathrm{CGH})$, revealing that alterations in these genomic regions might be responsible for the reduced survival of patients [24]. However, the poor prognosis of young breast cancer cannot be fully explained by these clinical and molecular factors and young age is still an independent predictor of prognosis for this disease [25].

In the present study, we performed a retrospective analysis that compared a series of clinicopathological features between young and older women with breast cancer and utilized the data from GEO database to investigate the gene expression pattern of young breast cancer in Asia, expecting to know more about the potential mechanisms and help to improve the prognosis of this disease.

\section{Materials and methods}

\section{Patients and clinical specimens}

The complete clinical data of 1125 patients diagnosed with breast cancer were collected. These patients accepted surgical operation and treatment at Nanfang Hospital, Southern Medical University in China between October 2009 and November 2013. According to Anders et al.'s definition that patients aged $\leq 45$ years were regarded as young breast cancer [26], 535 individuals were included in the young women group of our study. Patients aged $\geq 65$ years $(n=74)$ were allocated to the comparison group (older women group), which represented the elder, post-menopausal women. The remaining 516 patients between 45 and 65 years of age were not involved in our analysis because our objective was to compare breast cancer arising at the extremes of age.

Additionally, a consecutive series of breast cancer specimens were collected from primary tumor of 152 patients ( $n=130, \leq 45$ years; $n=22, \geq 65$ years) who did not accept neo-adjuvant chemotherapy but underwent breast-conserving surgery or modified radical mastectomy between January 2012 and August 2013. Breast cancer tissue and its corresponding adjacent normal breast tissue were obtained from each patient after excision by a surgeon and was immediately stored in liquid nitrogen until subsequent isolation of RNA and protein. This study had received approval from the Ethics Committee and all patients signed informed consents.

\section{Dataset and microarray analysis}

Two publicly-available datasets, GSE45255 [27] and GSE15852 [28], were downloaded from the Gene Expression Omnibus (National Center for Biotechnology Information, Bethesda, MD, USA). The breast cancer samples in GSE45255 were derived from the Institute Jules Bordet (IJB; Belgium), John Radcliffe Hospital (JRH; Oxford) and the National University Hospital (NUH, Singapore). The Singapore samples, comprising $74.2 \%$ Chinese, $13.4 \%$ Malays and $9.2 \%$ Indians, were utilized for further analysis. The breast caner samples in GSE15852 were collected from Malaysia, comprising $67.4 \%$ Malays, 24.6 \% Chinese and $7.3 \%$ Indians. After screening, 36 young patient samples and 21 older patient samples assayed by Affymetrix U133A GeneChips were used in the present study. The details of the datasets are presented in Additional file 1: Table S1.

Using $\mathrm{R}$ software package, gene expression profiling data was re-summarized by the RMA method [29] and Entrez gene-centric CDF files [30] (instead of original Affymetrix CDF files), which filtered out non-specific probes on the GeneChips and merged multiple probe sets representing the same Entrez gene into one probe set. The combat algorithm (CA) [31] was adopted to eliminate the batch effect of microarray data because these data were from two different batches of experiments. Significance analysis of microarray (SAM) [32] was performed to identify differentially expressed genes between young and older breast cancer tissues. Delta was set to 0.6 , and the threshold of FDR was set to 0.182 . The differentially expressed genes were further analyzed with GenCLiP on-line software [33, 34] (http:// ci.smu.edu.cn) to annotate gene functions and perform KEGG Pathway analysis.

\section{Extraction of total RNA and quantitative RT-PCR}

Total RNA was extracted from tissue samples with TRIzol (Invitrogen) according to the user's manual. Reverse transcription was performed using PrimeScript ${ }^{\mathrm{m}} \mathrm{RT}$ reagent Kit with gDNA Eraser (Perfect Real Time) (TaKaRa Code NO. RR047) and was run at $42{ }^{\circ} \mathrm{C}$ for 2 min to remove genomic DNA, then $37{ }^{\circ} \mathrm{C}$ for $15 \mathrm{~min}$ and $85{ }^{\circ} \mathrm{C}$ for $5 \mathrm{~s}$. Real-time PCR was performed using SYBR ${ }^{\circ}$ Premix Ex $\mathrm{Taq}^{\mathrm{Tm}}$ (Tli RNaseH Plus) (TaKaRa Code NO. RR420A) on an Mx3005P (Stratagene) with $10 \mathrm{~min}$ at $95{ }^{\circ} \mathrm{C}, 45$ cycles of $10 \mathrm{~s}$ at $95^{\circ} \mathrm{C}, 10 \mathrm{~s}$ at $60{ }^{\circ} \mathrm{C}$, and $15 \mathrm{~s}$ at $72{ }^{\circ} \mathrm{C}$ (data capture), and finally melting profile analysis $\left(55^{\circ} \mathrm{C}-95^{\circ} \mathrm{C}\right)$. Primer sequences were either derived from Primer Bank 
[35] or designed using primer5 primer design software (ESR1 forward primer: 5'-GGGAAGTATGGCTATGGAA TCTG-3', ESR1 reverse primer: 5'-TGGCTGGACACAT ATAGTCGTT-3'. GABRP forward primer: 5'-TTTCTC AGGCCCAATTTTGGT-3', GABRP reverse primer: 5'GCTGTCGGAGGTATATGGTGG-3'. CXCL13 forward primer: 5'-GCTTGAGGTGTAGATGTGTCC-3', CXCL13 reverse primer: 5'-CCCACGGGGCAAGATTTGAA-3'. GAPDH forward primer: 5'- CTGCACCACCAACTGC TT-3', GAPDH reverse primer: 5' - TTCTGGGTGGCAG TGATG-3'). GAPDH was employed to normalize the expression of target gene. The relative quantification (Fold Change) between different samples was compared between cancer and normal sample as well as between young women group and older women group according to the $2^{-\Delta \Delta C t}$ method as described by Livak and Schmittgen [36]. Quantitative RT-PCR (qRT-PCR) was conducted for each sample in triplicate.

\section{Western blotting}

Protein was extracted from cancer tissue and adjacent normal breast tissue using RIPA buffer with protease inhibitors and quantified using the BCA protein assay kit (Thermo Scientific, America). Protein $(20 \mu \mathrm{g})$ was loaded onto a $12 \%$ SDS-PAGE gel that was then transferred onto a PVDF membrane and incubated with rabbit monoclonal CXCL13 antibody (1:500; Abcam) at $4{ }^{\circ} \mathrm{C}$ overnight in blocker $(3 \%$ non-fat dry milk/BSA in TTBS). After washing, the membrane was incubated with mouse anti-rabbit HRP-conjugated secondary antibody (1:3,000; ProteinTech) for $2 \mathrm{~h}$ at room temperature. Protein was normalized with GAPDH (1:3,000; ProteinTech) and measured by densitometry using ECL detection (Bio-Rad, America).

\section{Immunohistochemistry assay}

Immunohistochemical staining was performed on formalin-fixed, paraffin-embedded tissue sections, which had been obtained for a routine diagnostics using standard techniques. The slides were dewaxed into xylene and rehydrated through graded alcohols. Following immersion in citrate buffer for antigen retrieval under pressure, the slides were placed in $3 \% \mathrm{H}_{2} \mathrm{O}_{2}$ for 15 min. The primary CXCL13 or CD45 antibody (Abcam) (diluted 1:20 in $3 \% \mathrm{BSA} / \mathrm{PBS}$ ) was incubated on the slides at $4{ }^{\circ} \mathrm{C}$ overnight. After washed in PBS, the mouse anti-rabbit HRPconjugated secondary antibody (ProteinTech) was applied for $30 \mathrm{~min}$. The slides were next incubated with DAB for 5 min and counterstained with $20 \%$ hematoxylin, dehydrated, cleared and mounted.

\section{Statistical analysis}

All statistical analyses were performed by the SPSS 20.0 statistical software package (SPSS Inc. Chicago, IL,
USA). $\chi^{2}$ test and Mann-Whitney $U$ test were employed to determine the differences of clinicopathological characteristics between young and older women groups. Wilcoxon sign test and Mann-Whitney $U$ test were used to compare gene expression levels of CXCL13, GABRP and ESR1 and protein expression levels of CXCL13 between different groups. Mann-Whitney $U$ test was used for the comparison of the immunohistochemistry results of CXCL13. Kruskal-Wallis $\mathrm{H}$ test, Mann-Whitney $U$ test and linear regression analysis were used to analyze the relationship between CXCL13 expression level and clinicopathological characteristics. Mann-Whitney $U$ test was used to compare the differences of clinicopathological characteristics between the groups with relatively low and high CXCL13 expression. The results were considered significant if $\mathrm{P}<0.05$.

\section{Results}

Clinicopathological characteristics of young breast cancer A total of 1125 women with age ranging from 20 to 87 years and a median of 46 years were diagnosed with breast cancer at Nanfang Hospital, Southern Medical University in China. Of them, 535 patients (47.6\%) were younger than or equal to 45 years and 74 patients (6.6\%) were older than or equal to 65 years.

The clinicopathological characteristics were comparatively analyzed between young women group ( $\leq 45$ years) and older women group ( $\geq 65$ years). As shown in Table 1, significant differences occurred in pathological type $(\mathrm{P}=0.001)$, tumor grade $(\mathrm{P}=0.009)$, lymph node status $(P=0.035)$, ER status $(P=0.041)$ and molecular subtypes $(\mathrm{P}=0.005)$ between the two groups. The proportion of IDC-NOS (invasive ductal carcinoma, not otherwise specified) was higher in young women group than in older women group (85.4 \% versus $72.9 \%)$, whereas the proportion of medullary carcinoma, mucinous carcinoma and other special types of invasive carcinoma was lower in young women group than in older women group (5.1\% versus $18.9 \%$ ). The proportion of luminal A subtype in young women group was lower than that of older women group (9.9\% versus $24.3 \%$ ), while the proportion of triple-negative subtype was higher in young women group (14.9\% versus $8.1 \%)$. Moreover, compared with their older counterparts, tumor grade, lymph node positive (45.8\% versus $32.4 \%$ ) and ER negative (37.7\% versus $25.7 \%$ ) were relatively higher in young group, but no difference was observed in tumor size, PR status, HER2 status and TNM staging.

\section{Differential gene expression pattern of young breast cancer} Based on two microarray datasets (GSE45255 and GSE15852) downloaded from GEO, 57 Asian breast cancer tissues collected from 36 young and 21 older patients were re-analyzed. SAM analysis showed 553 
Table 1 Clinical characteristic by age

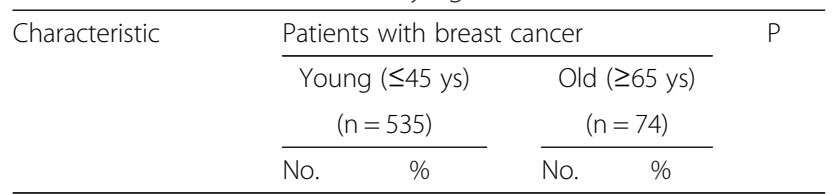

Age, years

Range

Median

Pathology

IDC-NOS

$\mathrm{ILC}$

DCIS

Others*

Tumor size, $\mathrm{mm}$

Range
Median

Tumor grade

1
2
3
Missing

Lymph node status

Positive

Negative

Missing

ER status

Positive

Negative

Missing

PR status

Positive

Negative

Missing

HER2 status

$\begin{array}{lllll}\text { Negative, 0-1+ } & 291 & 54.4 & 49 & 66.2 \\ \text { Equivocal, 2+ } & 122 & 22.8 & 13 & 17.6 \\ \text { Positive, 3+ } & 119 & 22.2 & 12 & 16.2 \\ \text { Missing } & 3 & 0.6 & --- & --- \\ \text { NM staging } & & & & \\ \text { O } & 34 & 6.4 & 4 & 5.4 \\ \text { I } & 134 & 25.1 & 21 & 28.4 \\ \text { II } & 219 & 40.9 & 29 & 39.2 \\ \text { III } & 120 & 22.4 & 16 & 21.6 \\ \text { IV } & 8 & 1.5 & 1 & 1.3 \\ \text { Missing } & 20 & 3.7 & 3 & 4.1\end{array}$

Table 1 Clinical characteristic by age (Continued)

\begin{tabular}{llllll}
\hline Subtypes & & & & & 0.005 \\
Luminal A & 53 & 9.9 & 18 & 24.3 & \\
Luminal B & 269 & 50.3 & 36 & 48.7 & \\
HER2 & 69 & 12.9 & 10 & 13.5 & \\
Triple negative & 80 & 14.9 & 6 & 8.1 & \\
Missing & 64 & 12.0 & 4 & 5.4 & \\
\hline
\end{tabular}

Abbreviations: IDC-NOS, invasive ductal carcinoma, not otherwise specified; ILC, invasive lobular carcinoma; DCIS, ductal carcinoma in situ

*Medullary carcinoma, mucinous carcinoma, tubular carcinoma, invasive papillary carcinoma and other special types of invasive carcinoma

significantly differentially expressed genes between young and older breast cancer; 81 genes were up-regulated and 472 genes were down-regulated in young breast cancer (Fig. 1a \& b, Additional file 2: Table S2) relative to older patients. Top 36 up-regulated genes and top 27 downregulated genes in young breast cancer were listed in Table 2 and Table 3 respectively. Of them, a set of genes related to immune function, such as CXCL13, IGHM, IGLL3P, IGJ and IGKC, were up-regulated in young patients with breast cancer. CXCL13 expression displayed the most significant difference $\left(\mathrm{FC}=2.64, \mathrm{P}=8.2 \times 10^{-4}\right.$ ) (Table 2). In addition, two identified genes, GABRP, positively associated with young breast cancer [37], and ESR1, down-regulated in young breast cancer [38], were also included (Tables $2 \& 3$ ).

Furthermore, 553 differentially expressed genes were analyzed by GenCLiP software. Notably, GO analysis revealed that CXCL13 was clustered into a small group of genes that were involved in a variety of cellular functions such as immune response, immune system process, cell death, programmed cell death and so on (Fig. 1b \& c). KEGG Pathway analysis showed the involvement of several signal pathways, such as calcium-, insulin-, Wntsignalling and so on (Additional file 3: Figure S1).

Therefore, our data suggest that CXCL13 may be an unidentified gene associated with young breast cancer and deserves further investigation.

\section{High CXCL13 mRNA and protein expression in young breast cancer}

To further validate our results, quantitative RT-PCR was performed to detect the expression levels of related 0.762 genes in 152 pairs of breast cancer tissues and their corresponding adjacent normal tissues $(n=130$, young women group; $\mathrm{n}=22$, older women group). The results displayed that CXCL13 mRNA expression was significantly up-regulated in $63.2 \%$ of breast cancer tissues (96 in $152, \mathrm{P}=0.045$ ) and indeed increased in young patients' tissues compared with older counterparts $(\mathrm{P}=0.011)$. Interestingly, qPCR also showed that GABRP expression was down-regulated $(67.8 \%, 103$ in $152, \mathrm{P}<0.0001)$ and ESR1 expression was up-regulated $(53.3 \%, 81$ in 152, 
A

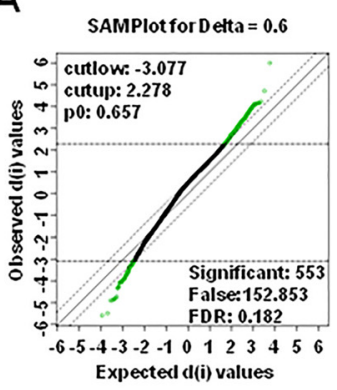

B

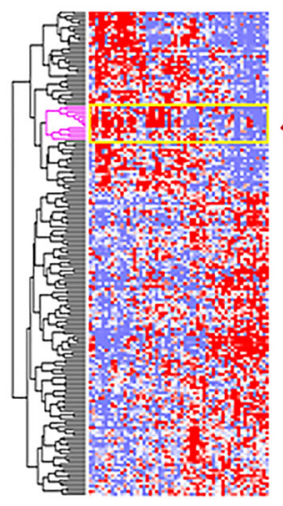

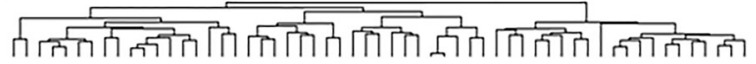

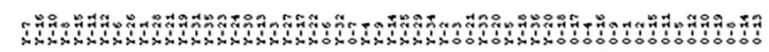

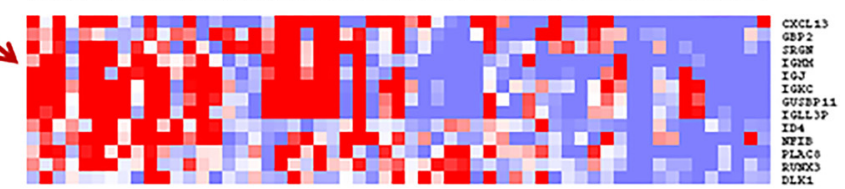

C

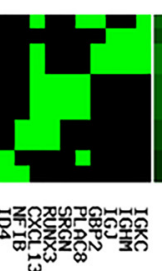

Fig. 1 Data mining of Gene expression profiles. a Significance analysis of microarray (SAM) was performed to identify differentially expressed genes between young and older breast cancer tissues. Delta was set to 0.6, and the threshold of FDR was set to 0.182. b Supervised hierarchical clustering of 553 differentially expressed genes. The heat map revealed the gene expression patterns between young patients and older patients. All samples were denoted in columns and genes were denoted in rows (gene symbols for a cluster of genes were listed on the right and the details of all differentially expressed genes could be found in Additional file 2: Table S2). The mapped expression levels for all genes were depicted using a color scale; highly expressed genes were indicated in red and lowly expressed in blue. c GO analysis of a cluster of differentially expressed genes was performed with GenCLiP software (http://ci.smu.edu.cn)

$\mathrm{P}=0.008)$ in these cancer tissues compared with their corresponding adjacent normal tissues. Particularly, GABRP increased $(P=0.005)$ while ESR1 decreased $(P=0.009)$ in young breast cancer (Fig. 2$)$.

Additionally, 12 pairs of specimen tissues $(n=6$, young women group; $n=6$, older women group) were randomly selected for the detection of CXCL13 protein expression by Western blotting. The results displayed that CXCL13 protein expression was significantly higher in cancer tissues than that of their corresponding adjacent normal tissues $(\mathrm{P}=0.015)$ and significantly up-regulated in young patients' tissues relative to older counterparts $(\mathrm{P}=0.041)$ (Fig. 3).

IHC staining of CXCL13 was next conducted in 48 paraffin sections randomly selected from formalin-fixed and routinely processed breast cancer tissues $(n=30$, young women group; $\mathrm{n}=18$, older women group). The protein expression levels were scored as $0,1,2$ and 3 for the negative, weak, moderate and high expression of CXCL13, respectively. We did observe that CXCL13 protein was expressed in young breast cancer in a higher level than that of their older counterparts $(P=0.015)$ (Fig. 4b, Table 4). It was expressed in tumor cells but not stromal cells (CD45 positive cells) (Fig. 4a, Additional file 4: Figure S2 \& Additional file 5: Figure S3).

Collectively, these data indicated a high CXCL13 expression level in young breast cancer.

\section{The correlation of high CXCL13 expression with clinicopathological features}

To explore the potential significance of CXCL13 in young breast cancer, correlation analysis was performed in 152 clinical tissue specimens with breast cancer to assess the association of CXCL13 expression with clinicopathological features, including tumor grade, lymph node status, ER status, PR status and HER2 status. Notably, the results showed that CXCL13 mRNA expression was obviously correlated with tumor grade, lymph node status or ER status; CXCL13 mRNA expression was significantly up-regulated in grade $2 / 3(\mathrm{P}=0.046 / \mathrm{P}=0.035)$, lymph node positive $(\mathrm{P}=0.012)$ or ER negative group $(\mathrm{P}=0.005)$ (Fig. 5a). Furthermore, linear regression analysis showed that age, lymph node status and ER status, were the independent factors of CXCL13 mRNA expression (Additional file 6: Table S3).

We also divided 138 microarrays from GSE45255 and GSE15852 into two groups according to their relative expression levels of CXCL13 (low expression group and high expression group, as shown in Fig. 5b). Upon comparing with low expression group, the significantly higher proportion of ER negative and younger patients appeared in the high expression group (Fig. 5c \& d). In addition, grade 3 and lymph node positive could be more frequently observed in the high CXCL13 expression group (Fig. 5c, Additional file 7: Figure S4) though no statistically significant differences were found.

\section{Discussion}

Breast cancer is a serious disease that affects the physical and mental health of women. In recent years, patients with breast cancer tend to be younger and the incidence of young breast cancer is increasing gradually [4, 9, 39]. In particular, the incidence and proportion of young breast cancer are much higher in Asia than in Western 
Table 2 Top 36 up-regulated genes in young patients with breast cancer

\begin{tabular}{|c|c|c|c|c|}
\hline NO. & Gene_symbol & Gene_name & FC & $\mathrm{P}$ \\
\hline 1 & KRT14 & Keratin 14 & 4.31 & $5.8 \times 10^{-7}$ \\
\hline 2 & GABRP & Gamma-aminobutyric acid (GABA) A receptor, pi & 2.82 & $7.2 \times 10^{-6}$ \\
\hline 3 & PROM1 & Prominin 1 & 2.76 & $2.6 \times 10^{-4}$ \\
\hline 4 & CXCL13 & Chemokine (C-X-C motif) ligand 13 & 2.64 & $8.2 \times 10^{-4}$ \\
\hline 5 & IGHM & Immunoglobulin heavy constant mu & 2.63 & $1.7 \times 10^{-4}$ \\
\hline 6 & IGLL3P & Immunoglobulin lambda-like polypeptide 3, pseudogene & 2.61 & $1.5 \times 10^{-3}$ \\
\hline 7 & MMP7 & Matrix metallopeptidase 7 (matriysin, uterine) & 2.52 & $2.3 \times 10^{-4}$ \\
\hline 8 & $\mid G J$ & Immunoglobulin J polypeptide & 2.40 & $8.0 \times 10^{-4}$ \\
\hline 9 & KRT17 & Keratin 17 & 2.37 & $7.4 \times 10^{-7}$ \\
\hline 10 & GUSBP11 & Glucuronidase, beta pseudogene 11 & 2.35 & $2.0 \times 10^{-3}$ \\
\hline 11 & KRT15 & Keratin 15 & 2.16 & $1.4 \times 10^{-3}$ \\
\hline 12 & KRT7 & Keratin 7 & 2.14 & $3.1 \times 10^{-3}$ \\
\hline 13 & TSPYL5 & TSPY-like 5 & 2.03 & $5.0 \times 10^{-5}$ \\
\hline 14 & IGKC & Immunoglobulin kappa constant & 1.97 & $2.4 \times 10^{-3}$ \\
\hline 15 & S100A2 & S100 calcium binding protein A2 & 1.91 & $2.1 \times 10^{-4}$ \\
\hline 16 & LDHB & Lactate dehydrogenase B & 1.85 & $6.4 \times 10^{-4}$ \\
\hline 17 & SFRP1 & Secreted frizzled-related protein 1 & 1.83 & $5.5 \times 10^{-4}$ \\
\hline 18 & KRT5 & Keratin 5 & 1.79 & $6.1 \times 10^{-4}$ \\
\hline 19 & $\mathrm{CDH} 3$ & Cadherin 3, type 1, P-cadherin (placental) & 1.78 & $9.9 \times 10^{-6}$ \\
\hline 20 & RND3 & Rho family GTPase 3 & 1.78 & $9.7 \times 10^{-6}$ \\
\hline 21 & SYNM & Synemin, intermediate filament protein & 1.76 & $1.8 \times 10^{-4}$ \\
\hline 22 & $\mathrm{KIT}$ & V-kit Hardy-Zuckerman 4 feline sarcoma viral oncogene homolog & 1.75 & $7.0 \times 10^{-6}$ \\
\hline 23 & KRT6B & Keratin 6B & 1.75 & $1.3 \times 10^{-4}$ \\
\hline 24 & MT1X & Metallothionein $1 \mathrm{X}$ & 1.74 & $1.8 \times 10^{-3}$ \\
\hline 25 & AMIGO2 & Adhesion molecule with Ig-like domain 2 & 1.65 & $2.1 \times 10^{-3}$ \\
\hline 26 & SLC6A14 & Solute carrier family 6 (amino acid transporter), member 14 & 1.63 & $4.3 \times 10^{-4}$ \\
\hline 27 & RGS2 & Regulator of G-protein signaling 2, $24 \mathrm{kDa}$ & 1.61 & $9.3 \times 10^{-4}$ \\
\hline 28 & SRGN & Serglycin & 1.60 & $2.9 \times 10^{-3}$ \\
\hline 29 & DDIT4 & DNA-damage-inducible transcript 4 & 1.60 & $1.4 \times 10^{-3}$ \\
\hline 30 & NFIB & Nuclear factor I/B & 1.58 & $1.8 \times 10^{-3}$ \\
\hline 31 & DTX4 & Deltex homolog 4 (Drosophila) & 1.58 & $1.4 \times 10^{-4}$ \\
\hline 32 & CSDA & Cold shock domain protein A & 1.57 & $3.8 \times 10^{-4}$ \\
\hline 33 & GBP2 & Guanylate binding protein 2, interferon-inducible & 1.54 & $1.8 \times 10^{-3}$ \\
\hline 34 & ITM2A & Integral membrane protein $2 \mathrm{~A}$ & 1.53 & $1.9 \times 10^{-3}$ \\
\hline 35 & PADI2 & Peptidyl arginine deiminase, type II & 1.52 & $1.4 \times 10^{-4}$ \\
\hline 36 & RBMS1 & RNA binding motif, single stranded interacting protein 1 & 1.52 & $3.2 \times 10^{-4}$ \\
\hline
\end{tabular}

Abbreviations: $F C$, Fold change

countries [3-8], suggesting the differences in the incidence of young breast cancer between different ethnic groups. In the present study, 1125 breast cancer patients were collected from October 2009 and November 2013 and 535 patients were observed to be younger than or equal to 45 years, occupying $47.6 \%$ of all the patients. This is consistent with the data from Saudi Arabia [8], providing additional evidence for the higher proportion of young breast cancer in Asia.

A retrospective analysis was performed in a large cohort of patients to compare the differences between young women group ( $\leq 45$ years) and older women group ( $\geq 65$ years). Firstly, we found a statistical difference in pathological types between these two groups; 
Table 3 Top 27 down-regulated genes in young patients with breast cancer

\begin{tabular}{|c|c|c|c|c|}
\hline NO. & Gene_symbol & Gene_name & FC & $P$ \\
\hline 1 & NAT1 & $\mathrm{N}$-acetyltransferase 1 (arylamine $\mathrm{N}$-acetyltransferase) & 0.37 & $2.3 \times 10^{-3}$ \\
\hline 2 & GRIA2 & Glutamate receptor, ionotropic, AMPA 2 & 0.45 & $1.5 \times 10^{-2}$ \\
\hline 3 & C6orf211 & Chromosome 6 open reading frame 211 & 0.49 & $9.9 \times 10^{-3}$ \\
\hline 4 & PSD3 & Pleckstrin and Sec7 domain containing 3 & 0.49 & $6.1 \times 10^{-4}$ \\
\hline 5 & GFRA1 & GDNF family receptor alpha 1 & 0.49 & $3.4 \times 10^{-3}$ \\
\hline 6 & EVL & Enah/Vasp-like & 0.50 & $1.0 \times 10^{-3}$ \\
\hline 7 & SCUBE2 & Signal peptide, CUB domain, EGF-like 2 & 0.51 & $2.2 \times 10^{-2}$ \\
\hline 8 & DNAJC12 & DnaJ (Hsp40) homolog, subfamily C, member 12 & 0.52 & $1.9 \times 10^{-3}$ \\
\hline 9 & KCNE4 & Potassium voltage-gated channel, Iskrelated family, member 4 & 0.52 & $7.5 \times 10^{-3}$ \\
\hline 10 & ECM1 & Extracellular matrix protein 1 & 0.52 & $1.8 \times 10^{-3}$ \\
\hline 11 & TBC1D9 & TBC1 domain family, member 9 (with GRAM domain) & 0.53 & $4.6 \times 10^{-4}$ \\
\hline 12 & CYP2B7P1 & Cytochrome P450, family 2, subfamily B, polypeptide 7 pseudogene 1 & 0.53 & $7.3 \times 10^{-3}$ \\
\hline 13 & ESR1 & Estrogen receptor 1 & 0.54 & $8.3 \times 10^{-8}$ \\
\hline 14 & CA12 & Carbonic anhydrase XII & 0.55 & $1.2 \times 10^{-3}$ \\
\hline 15 & MYB & V-myb myeloblastosis viral oncogene homolog (avian) & 0.56 & $1.4 \times 10^{-2}$ \\
\hline 16 & PLAT & Plasminogen activator, tissue & 0.59 & $2.7 \times 10^{-2}$ \\
\hline 17 & PGR & Progesterone receptor & 0.59 & $1.6 \times 10^{-2}$ \\
\hline 18 & CLGN & Calmegin & 0.60 & $2.5 \times 10^{-3}$ \\
\hline 19 & SLC44A4 & Solute carrier family 44 , member 4 & 0.61 & $8.1 \times 10^{-3}$ \\
\hline 20 & REEP1 & Receptor accessory protein 1 & 0.62 & $9.6 \times 10^{-4}$ \\
\hline 21 & $A R$ & Androgen receptor & 0.64 & $9.7 \times 10^{-4}$ \\
\hline 22 & F7 & Coagulation factor VII (serum prothrombin conversion accelerator) & 0.64 & $2.1 \times 10^{-3}$ \\
\hline 23 & CCDC170 & Coiled-coil domain containing 170 & 0.64 & $1.3 \times 10^{-4}$ \\
\hline 24 & SELENBP1 & Selenium binding protein 1 & 0.65 & $2.3 \times 10^{-2}$ \\
\hline 25 & PRKAR2B & Protein kinase, cAMP-dependent, regulatory, type II, beta & 0.65 & $2.0 \times 10^{-3}$ \\
\hline 26 & GLCE & Glucuronic acid epimerase & 0.66 & $2.0 \times 10^{-4}$ \\
\hline 27 & RNASE4 & Ribonuclease, RNase A family, 4 & 0.66 & $9.5 \times 10^{-4}$ \\
\hline
\end{tabular}

Abbreviations: $F C$, Fold change

invasive cancer types were more frequently observed in young patient group. Secondly, we confirmed the higher tumor grade, higher lymph node positivity, and lower ER positivity in young breast cancer. These data indicated that young breast cancer was more aggressive and probably associated with poor prognosis. Thirdly, we observed that the pattern of molecular subtypes in young women group was obviously different from that of older women group; luminal A subtype was less and triple-negative subtype was more in young patients. However, we noticed a much lower percentage of Luminal $\mathrm{A}$ and a higher percentage of Luminal B patients in our cohort than that of previous reports [40]. This might be caused by our assessment of molecular subtypes based on the standard of Ki67 $<14 \%$ or $\geq 14 \%$ in the St Gallen International Expert Consensus [41] in the absence of a specific standard for Ki67 in the Department of pathology of our hospital. Fortunately, the result could display the difference in molecular subtypes between two groups, consistent with previous report [42]. A previous study reported that luminal A subtype breast cancer had the best prognosis, while the triple-negative subtype patients had the worst prognosis [40]. Thus, the unfavorable prognosis of young breast cancer may be attributed to the different constitution of molecular subtypes. However, the retrospective analysis did not show any differences in tumor size, PR status, HER2 status and TNM staging between two groups. By carefully analyzing the patient-based data, we observed that most of patients in older women group came from the villages where lacked self-care awareness and routine mammography screen, so these patients failed to see a doctor in time when they had a suspicious breast mass, easily leading to a larger tumor with more lymph node metastasis. This may be one of reasons why we could not observe a significant difference in tumor size and TNM 


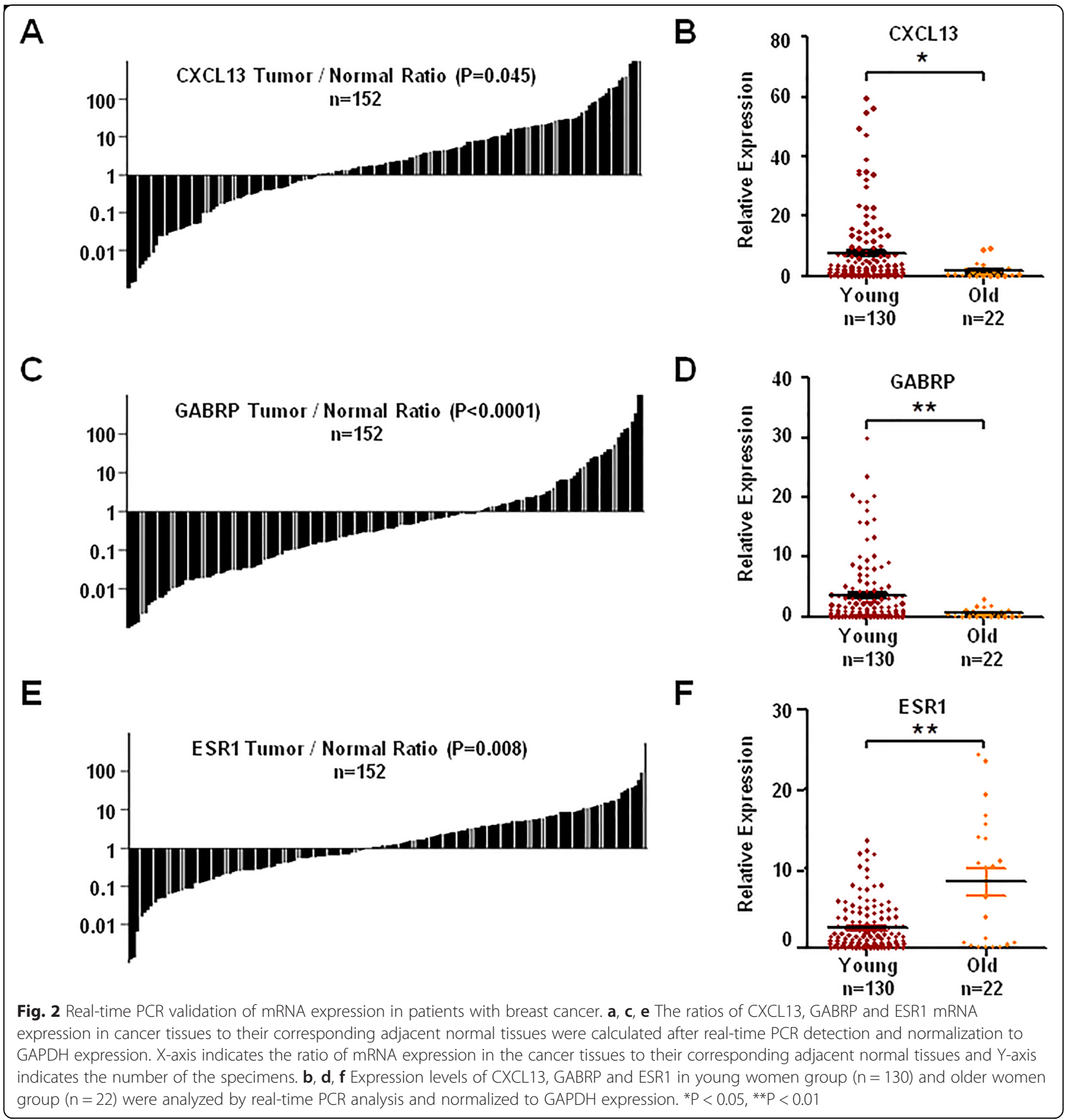

staging between young and older women patients. Moreover, probably due to relatively fewer samples in older women group, the difference in HER2 expression between two groups did not reach statistical significance though a trend towards a higher level of HER2 expression appeared in young breast cancer.

To provide an insight into the potential mechanism of tumor biology in young breast cancer, we re-analyzed two sets of microarray data downloaded from GEO. We found 81 up-regulated genes and 472 down-regulated genes in young breast cancer compared with older breast cancer. Notably, GABRP [37] and ESR1 [38] previously reported to be related to young breast cancer were included in these differentially expressed genes and validated by qRT-PCR, proving the reliability of our data mining and allocation of samples. More interestingly, in addition to these two genes, a set of genes related to immune function, such as CXCL13, IGHM, IGLL3P, IGJ and IGKC, were observed to be significantly up-regulated in young breast cancer and CXCL13 showed the most 

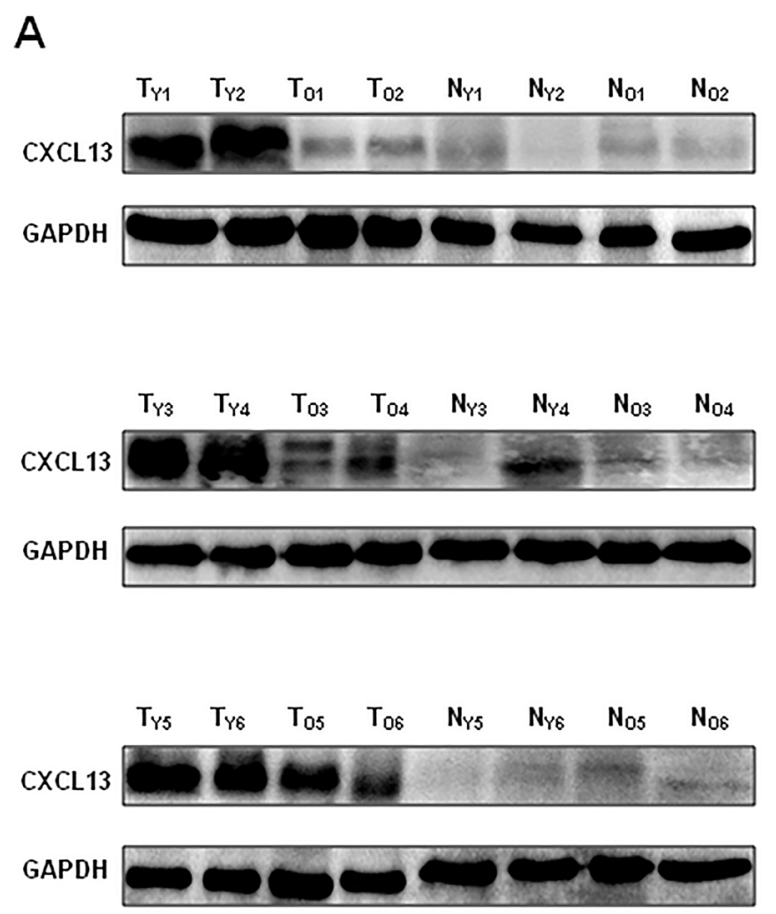

B
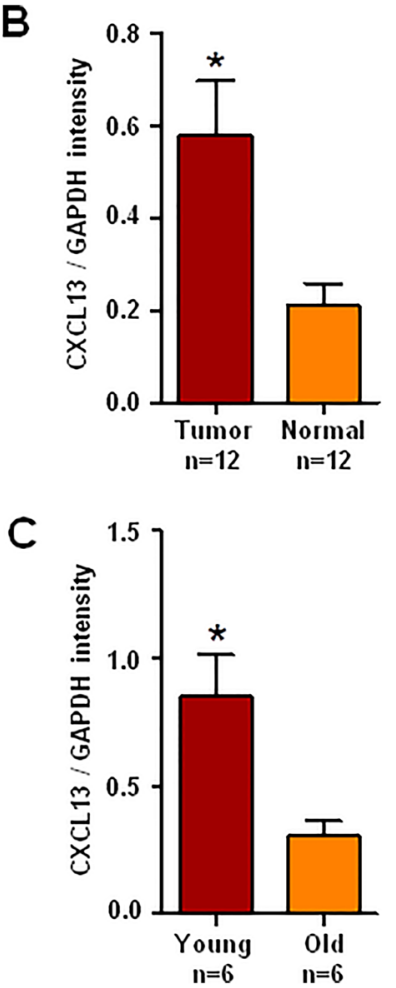

Fig. 3 Western blotting detection of CXCL13 protein in patients with breast cancer. a Expression levels of CXCL13 protein were assessed by Western blotting analysis and normalized to GAPDH. $T_{Y_{1-6}}$ and $\mathrm{T}_{\mathrm{O1-6}}$ represented randomly selected cancer tissues from young women group and older women group, respectively, and $\mathrm{N}_{Y_{1-6}}$ and $\mathrm{N}_{\mathrm{O}_{1-6}}$ represented the randomly selected corresponding adjacent normal tissues from young women group and older women group, respectively. $\mathbf{b}$ A semi-quantitative analysis of the Western blotting of CXCL13 protein was performed between cancer tissues $(n=12)$ and their corresponding adjacent normal tissues $(n=12)$. c A semi-quantitative analysis of the Western blotting of CXCL13 protein in cancer tissues between young patients $(n=6)$ and their older counterparts $(n=6) .{ }^{*} P<0.05$

significant difference, implying that abnormality of immune functions may be a potential risk factor for young breast cancer. Moreover, we observed that CXCL13 was clustered with some differentially expressed genes that were involved in a variety of cellular functions such as immune response, immune system process, cell death, programmed cell death and so on by GO analysis, implying that CXCL13 may play multiple roles in young breast cancer.

The functions of CXC-chemokines are initially thought to be chemoattraction and activation of leukocytes in diverse immunological responses [43], but nowadays the important roles of CXC-chemokine ligands and their corresponding receptors in neoplastic transformation, cancer cell migration, invasion, and metastasis have been proved by increasing evidences [44-47]. For example, CXCL12 promoted cell migration, cell growth, and invasion of ovarian cancer cells [48]. CXCR1 and CXCR2 could stimulate prostate cancer progression through autocrine signaling of cancer cells [46]. CXCL1 and CXCL8 could act as autocrine growth factors [49-51]. CXCL13 is one of important chemokines. It is also known as BLC or BCA1 $[52,53]$ and is a marker of $\mathrm{B}$ lymphocyte aggregation, playing a key role in homing, migration and accumulation of B lymphocyte [52] by specially binding with CXCR5 [54]. The impact of CXCL13/CXCR5 on various types of cancers including breast cancer has recently attracted much interest [55-60]. Depending on PI3Kp110, Src and FAK, the interaction of CXCR5 with its specific ligand-CXCL13, could promote prostate cancer cell invasion, migration, and differential matrix metalloproteinase (MMP) expression [59]. Panse et al.'s microarray analysis, followed by the validation in breast cancer samples and cell lines, revealed an overexpressed CXCL13 in breast cancer tissues. Panse et al. detected a significantly elevated serum concentration of CXCL13 in breast cancer patients with metastatic disease as compared with controls and diseasefree patients [55]. Razmkhah's research showed a significantly high expression level of CXCR5 transcript in lymph node positive patients with stage III compared to those with stage II tumors, and a higher mRNA expression of CXCL13 in lymph node positive samples compared to lymph node negative samples though the difference was not significant [61]. A recent study provides evidence that co-expression of CXCL13 and CXCR5 shows a significant 


\section{A}
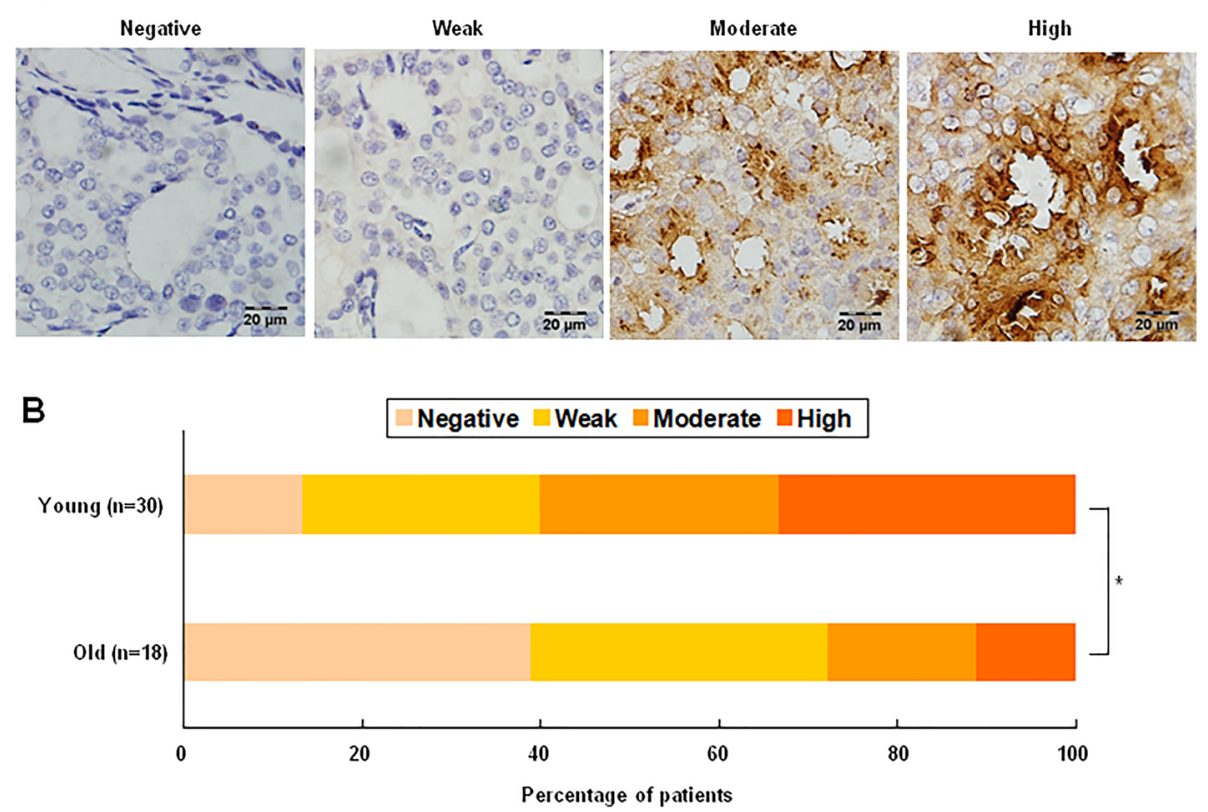

Fig. 4 Immunohistochemistry detection of CXCL13 protein in patients with breast cancer. a Representative IHC of breast cancer samples, showing the negative, weak, moderate and high expression level of CXCL13, respectively. $\mathbf{b}$ The percentage of patients with the negative, weak, moderate and high expression of CXCL13 protein in young and older women group. ${ }^{*} \mathrm{P}<0.05$

correlation with lymph node metastasis and CXCL13 has the EMT-inducing potential [62]. In the present study, to validate the possible roles of CXCL13 in young breast cancer, we carried out multiple detections of CXCL13 expression at either mRNA or protein level in a relatively large set of clinical tissue specimens from patients with breast cancer. Our results were consistent with these previous reports, indicating a highly expressed CXCL13 in breast cancer though these data may be affected by the existence of fat tissue and adenocarcinoma cells in adjacent normal breast tissue. Impressively, we further observed that this gene was highly expressed in young breast cancer compared with their older counterparts. The clinical correlation analysis and linear regression analysis supported the potential significance of CXCL13 in young breast cancer. This may be helpful for establishing a potential association between CXCL13 and young breast cancer, explaining why young patients with breast cancer are prone to develop

Table 4 Expression status of CXCL13 in patients with breast cancer by immunohistochemistry

\begin{tabular}{llll}
\hline CXCL13 & \multicolumn{2}{l}{ Patients with breast cancer } & $P$ \\
\cline { 2 - 3 } & Young $(\leq 45$ years $)(n=30)$ & Old $(\geq 65$ years $)(n=18)$ & \\
\hline 0 & 4 & 7 & 0.015 \\
1 & 8 & 6 & \\
2 & 8 & 3 & \\
3 & 10 & 2 & \\
\hline
\end{tabular}

metastasis and why young age at diagnosis are associated with poor prognosis.

However, to date there have been two different opinions; one is that immune cells in tumor environment play a primary role of tumor rejection and the upregulation of some immune genes are related to the better prognosis [63-67]. Another is that they sometime show pro-tumor rather than anti-tumor properties in tumor microenvironment [68-70]. Similarly, there are opposite opinions or data about the role of CXCL13 in cancer. Razis et al. showed that activation of CXCL13/ CXCR5 axis was associated with the determinants of poor prognosis but improved the outcome of the HER2 overexpressing subpopulation [71]. The good prognostic value of CXCL13, particularly in ER- and HER2+ breast cancer, was also confirmed by Gu-Trantien et al.[72]. These data suggests less obvious roles of CXCL13 in the poor prognosis of young breast cancer. To our knowledge, these conflicting data yielded may be due to the possibility that chemokines exert different functions in different environments or immune states influenced by many factors such as race, age, disease, and so on. Therefore, a long term and larger sample-size study in Asian people with breast cancer is deserved to further validate our data.

It has been reported that chemokines produced by solid epithelial tumors such as ovarian cancer [73] and breast cancer [74, 75], were associated with leukocyte infiltration, especially macrophage infiltration $[76,77]$. 
A

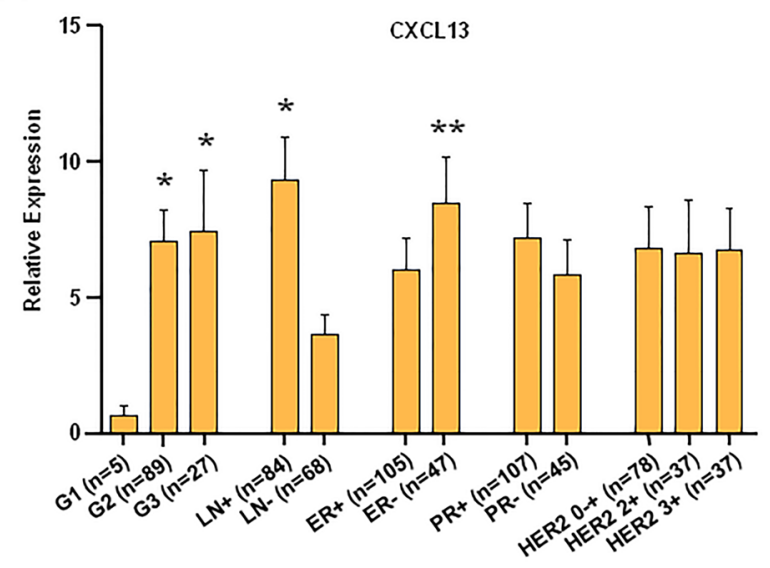

C

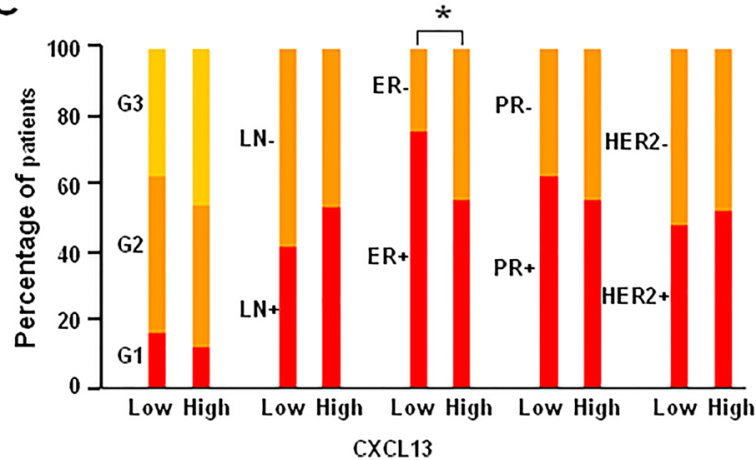

B

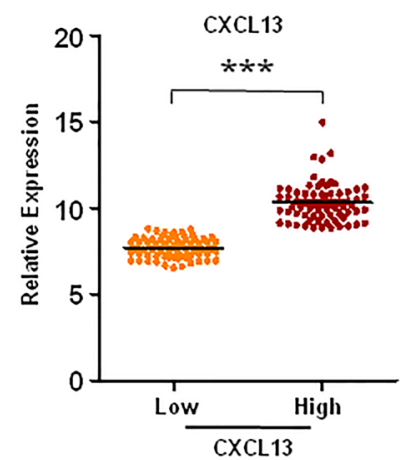

D

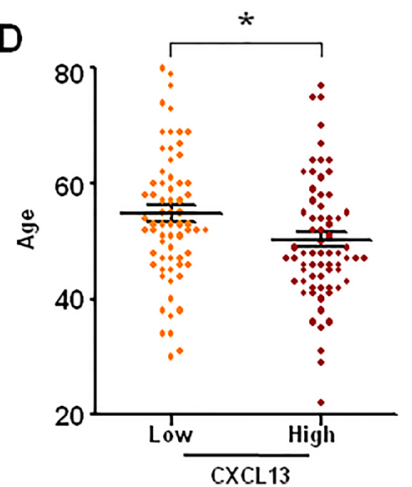

Fig. 5 Analysis of the correlation of CXCL13 expression with clinicopathological features. a The CXCL13 mRNA expression in 152 clinical tissue specimens was compared according to clinicopathological features. b, c, d 138 microarrays from GSE45255 and GSE15852 were divided into two groups according to their relative expression levels of CXCL13 (low expression group and high expression group). The CXCL13 expression and clinicopathological features were compared between these two groups. ${ }^{* P}<0.05$, ${ }^{* *} \mathrm{P}<0.01$, ${ }^{* *} P<0.001$

Chemokines were found in colorectal cancer to be associated with the accumulation of tumor-associated macrophages (TAM) that favor tumor progression instead of normal immune functions [78]. These studies hint the existence of a possible relationship between high CXCL13 expression in young breast cancer and TAM accumulation in tumor microenvironment. We are planning to elucidate it in future.

\section{Conclusion}

In summary, the present study investigated the proportion of young breast cancer in Asia and re-confirmed some unfavorable factors related to the poor prognosis in young breast cancer. Using the data mining of gene expression profiles and the clinical sample-based validations, we first showed that CXCL13 was highly expressed in young breast cancer, and closely associated with some prognostic factors including lymph node positive and ER negative in young breast cancer. CXCL13 may be a potential unfavorable factor for young breast cancer in Asia, though its prognostic value remains unclear.

\section{Additional files}

Additional file 1: Table S1. Clinical characteristic of gene microarray with breast cancer.

Additional file 2: Table S2. 553 differentially expressed genes identified by SAM Method.

Additional file 3: Figure S1. KEGG pathway analysis of differentially expressed genes.

Additional file 4: Figure S2. Immunohistochemistry detection of CXCL13 protein in patients with breast cancer.

Additional file 5: Figure S3. Immunohistochemistry detection showing the location of CXCL13 protein.

Additional file 6: Table S3. Linear regression analysis of the correlation of CXCL13 expression with clinicopathological features.

Additional file 7: Figure S4. Analysis of the correlation of CXCL13 expression with tumor size.

\section{Competing interests}

The authors declare that they have no competing interests.

\section{Authors' contributions}

LC and GY carried out all experiments and drafted the manuscript. ZH performed the data mining of gene expression profiles. $X L$ and $J L$ performed the statistical analysis. XH, YC and WL helped to collect the clinical information and specimens of breast cancer patients. $\mathrm{XL}$ and CY participated in the design 
of the study and helped to draft the manuscript. All authors read and approved the final manuscript.

\section{Acknowledgement}

This work was fully sponsored by National Science and Technology Support Program of China with grant number 2013BAI05B05.

\section{Author details \\ 'Breast Center, Nanfang Hospital, Southern Medical University, Guangzhou, Guangdong 510515, People's Republic of China. ${ }^{2}$ Cancer Research Institute and the Provincial Key Laboratory of Functional Proteomics, Southern Medical University, Guangzhou, Guangdong 510515, People's Republic of China. ${ }^{3}$ Department of Laboratory Medicine, the Third Affiliated Hospital, Southern Medical University, Guangzhou, Guangdong 510630, People's Republic of China.}

\section{Received: 9 November 2014 Accepted: 6 May 2015} Published online: 20 May 2015

\section{References}

1. Jemal A, Bray F, Center MM, Ferlay J, Ward E, Forman D. Global cancer statistics. CA Cancer J Clin. 2011;61:69-90.

2. Siegel R, Ma J, Zou Z, Jemal A. Cancer statistics, 2014. CA Cancer J Clin. 2014;64:9-29.

3. Shannon C, Smith IE. Breast cancer in adolescents and young women. Eur J Cancer. 2003:39:2632-42.

4. Desantis C, Ma J, Bryan L, Jemal A. Breast cancer statistics, 2013. CA Cancer J Clin. 2014;64:52-62.

5. Bandi P, Boone M, Brinton L, Buchert S. Breast cancer facts \& figures 2009-2010. Atlanta: American Cancer Society; 2010.

6. Agarwal G, Pradeep PV, Aggarwal V, Yip CH, Cheung PS. Spectrum of breast cancer in Asian women. World J Surg. 2007;31:1031-40.

7. Jeon YW, Choi JE, Park HK, Kim KS, Lee JY, Suh YJ. Impact of local surgical treatment on survival in young women with $\mathrm{T} 1$ breast cancer: long-term results of a population-based cohort. Breast Cancer Res Treat. 2013;138:475-84.

8. Al-Eid HS BSAA. Cancer Incidence Report Saudi Arabia 2005. 2011.

9. Agnese DM, Yusuf F, Wilson JL, Shapiro CL, Lehman A, Burak WJ. Trends in breast cancer presentation and care according to age in a single institution. Am J Surg. 2004;188:437-9.

10. Bleyer A, Barr R, Hayes-Lattin B, Thomas D, Ellis C, Anderson B. The distinctive biology of cancer in adolescents and young adults. Nat Rev Cancer. 2008:8:288-98.

11. Anders CK, Johnson R, Litton J, Phillips M, Bleyer A. Breast cancer before age 40 years. Semin Oncol. 2009;36:237-49.

12. Hickey M, Peate M, Saunders CM, Friedlander M. Breast cancer in young women and its impact on reproductive function. Hum Reprod Update. 2009;15:323-39.

13. Kim JK, Kwak BS, Lee JS, Hong SJ, Kim HJ, Son BH, et al. Do very young Korean breast cancer patients have worse outcomes? Ann Surg Oncol. 2007:14:3385-91.

14. Rapiti E, Fioretta G, Verkooijen HM, Vlastos G, Schafer P, Sappino AP, et al. Survival of young and older breast cancer patients in Geneva from 1990 to 2001. Eur J Cancer. 2005:41:1446-52.

15. Vrieling C, Collette L, Fourquet A, Hoogenraad WJ, Horiot JC, Jager JJ, et al. Can patient-, treatment- and pathology-related characteristics explain the high local recurrence rate following breast-conserving therapy in young patients? Eur J Cancer. 2003;39:932-44.

16. Xiong Q, Valero V, Kau V, Kau SW, Taylor S, Smith TL, et al. Female patients with breast carcinoma age 30 years and younger have a poor prognosis: the M.D. Anderson Cancer Center experience. Cancer. 2001;92:2523-8.

17. Shimauchi A, Nemoto K, Ogawa Y, Kakuto Y, Sakayauchi T, Takai Y, et al. Long-term outcome of breast-conserving therapy for breast cancer. Radiat Med. 2005;23:485-90.

18. Gajdos C, Tartter PI, Bleiweiss IJ, Bodian C, Brower ST. Stage 0 to stage III breast cancer in young women. J Am Coll Surg. 2000;190:523-9.

19. Jmor S, Al-Sayer H, Heys SD, Payne S, Miller I, Ah-See A, et al. Breast cancer in women aged 35 and under: prognosis and survival. J R Coll Surg Edinb. 2002:47:693-9.

20. Carvalho FM, Bacchi LM, Santos PP, Bacchi CE. Triple-negative breast carcinomas are a heterogeneous entity that differs between young and old patients. Clinics (Sao Paulo). 2010;65:1033-6.
21. Colleoni M, Rotmensz N, Robertson C, Orlando L, Viale G, Renne G, et al. Very young women (<35 years) with operable breast cancer: features of disease at presentation. Ann Oncol. 2002;13:273-9.

22. Chen W, Pan K, Ouyang T, Li J, Wang T, Fan Z, et al. BRCA1 germline mutations and tumor characteristics in Chinese women with familial or early-onset breast cancer. Breast Cancer Res Treat. 2009;117:55-60.

23. Kroman N, Jensen MB, Wohlfahrt J, Mouridsen HT, Andersen PK, Melbye M. Factors influencing the effect of age on prognosis in breast cancer: population based study. BMJ. 2000;320:474-8.

24. Weber-Mangal S, Sinn HP, Popp S, Klaes R, Emig R, Bentz M, et al. Breast cancer in young women ( $<$ or $=35$ years): Genomic aberrations detected by comparative genomic hybridization. Int J Cancer. 2003; 107:583-92

25. Oh JL, Bonnen M, Outlaw ED, Schechter NR, Perkins GH, Strom EA, et al. The impact of young age on locoregional recurrence after doxorubicin-based breast conservation therapy in patients 40 years old or younger: How young is "young"? Int J Radiat Oncol Biol Phys. 2006;65:1345-52.

26. Anders CK, Acharya CR, Hsu DS, Broadwater G, Garman K, Foekens JA, et al. Age-specific differences in oncogenic pathway deregulation seen in human breast tumors. PLoS One. 2008;3:e1373.

27. Nagalla S, Chou JW, Willingham MC, Ruiz J, Vaughn JP, Dubey P, et al. Interactions between immunity, proliferation and molecular subtype in breast cancer prognosis. Genome Biol. 2013;14:R34.

28. Pau NI, Zakaria Z, Muhammad R, Abdullah N, Ibrahim N, Aina EN, et al. Gene expression patterns distinguish breast carcinomas from normal breast tissues: the Malaysian context. Pathol Res Pract. 2010;206:223-8.

29. Irizarry RA, Hobbs B, Collin F, Beazer-Barclay YD, Antonellis KJ, Scherf U, et al. Exploration, normalization, and summaries of high density oligonucleotide array probe level data. Biostatistics. 2003:4:249-64.

30. Dai M, Wang P, Boyd AD, Kostov G, Athey B, Jones EG, et al. Evolving gene/ transcript definitions significantly alter the interpretation of GeneChip data. Nucleic Acids Res. 2005;33:e175.

31. Johnson WE, Li C, Rabinovic A. Adjusting batch effects in microarray expression data using empirical Bayes methods. Biostatistics. 2007:8:118-27.

32. Tusher VG, Tibshirani R, Chu G. Significance analysis of microarrays applied to the ionizing radiation response. Proc Natl Acad Sci U S A. 2001;98:5116-21.

33. Huang ZX, Tian HY, Hu ZF, Zhou YB, Zhao J, Yao KT. GenCLiP: a software program for clustering gene lists by literature profiling and constructing gene co-occurrence networks related to custom keywords. BMC Bioinformatics. 2008;9:308.

34. Wang JH, Zhao LF, Lin P, Su XR, Chen SJ, Huang LQ, et al. GenCLiP 2.0: a web server for functional clustering of genes and construction of molecular networks based on free terms. Bioinformatics. 2014;30:2534-6.

35. Wang X, Seed B. A PCR primer bank for quantitative gene expression analysis. Nucleic Acids Res. 2003;31:e154.

36. Livak KJ, Schmittgen TD. Analysis of relative gene expression data using real-time quantitative PCR and the 2(-Delta Delta C(T)) Method. Methods. 2001;25:402-8

37. Symmans WF, Fiterman DJ, Anderson SK, Ayers M, Rouzier R, Dunmire V, et al. A single-gene biomarker identifies breast cancers associated with immature cell type and short duration of prior breastfeeding. Endocr Relat Cancer. 2005;12:1059-69.

38. Anders CK, Hsu DS, Broadwater G, Acharya CR, Foekens JA, Zhang Y, et al. Young age at diagnosis correlates with worse prognosis and defines a subset of breast cancers with shared patterns of gene expression. J Clin Oncol. 2008:26:3324-30.

39. Chung M, Chang HR, Bland Kl, Wanebo HJ. Younger women with breast carcinoma have a poorer prognosis than older women. Cancer. 1996;77:97-103.

40. Carey LA, Perou CM, Livasy CA, Dressler LG, Cowan D, Conway K, et al. Race, breast cancer subtypes, and survival in the Carolina Breast Cancer Study. JAMA. 2006;295:2492-502.

41. Goldhirsch A, Wood WC, Coates AS, Gelber RD, Thurlimann B, Senn HJ. Strategies for subtypes-dealing with the diversity of breast cancer: highlights of the St. Gallen International Expert Consensus on the Primary Therapy of Early Breast Cancer 2011. Ann Oncol. 2011;22:1736-47.

42. Ihemelandu CU, Leffall LJ, Dewitty RL, Naab TJ, Mezghebe HM, Makambi KH, et al. Molecular breast cancer subtypes in premenopausal and postmenopausal African-American women: age-specific prevalence and survival. J Surg Res. 2007;143:109-18.

43. Balkwill F. Cancer and the chemokine network. Nat Rev Cancer. 2004;4:540-50. 
44. Zlotnik A. Chemokines in neoplastic progression. Semin Cancer Biol. 2004;14:181-5.

45. Longo-Imedio MI, Longo N, Trevino I, Lazaro P, Sanchez-Mateos P. Clinical significance of CXCR3 and CXCR4 expression in primary melanoma. Int J Cancer. 2005;117:861-5.

46. Murphy C, McGurk M, Pettigrew J, Santinelli A, Mazzucchelli R, Johnston PG, et al. Nonapical and cytoplasmic expression of interleukin-8, CXCR1, and CXCR2 correlates with cell proliferation and microvessel density in prostate cancer. Clin Cancer Res. 2005;11:4117-27.

47. Keeley EC, Mehrad B, Strieter RM. CXC chemokines in cancer angiogenesis and metastases. Adv Cancer Res. 2010;106:91-111.

48. Scotton CJ, Wilson JL, Scott K, Stamp G, Wilbanks GD, Fricker S, et al. Multiple actions of the chemokine CXCL12 on epithelial tumor cells in human ovarian cancer. Cancer Res. 2002;62:5930-8.

49. Dhawan P, Richmond A. Role of CXCL1 in tumorigenesis of melanoma J Leukoc Biol. 2002;72:9-18.

50. Zhou Y, Zhang J, Liu Q, Bell R, Muruve DA, Forsyth P, et al. The chemokine GRO-alpha (CXCL1) confers increased tumorigenicity to glioma cells. Carcinogenesis. 2005;26:2058-68.

51. Singh S, Singh AP, Sharma B, Owen LB, Singh RK. CXCL8 and its cognate receptors in melanoma progression and metastasis. Future Oncol. 2010;6:111-6.

52. Gunn MD, Ngo VN, Ansel KM, Ekland EH, Cyster JG, Williams LT. A B-cellhoming chemokine made in lymphoid follicles activates Burkitt's lymphoma receptor-1. Nature. 1998:391:799-803.

53. Legler DF, Loetscher M, Roos RS, Clark-Lewis I, Baggiolini M, Moser B. B cell-attracting chemokine 1, a human CXC chemokine expressed in lymphoid tissues, selectively attracts B lymphocytes via BLR1/CXCR5. J Exp Med. 1998;187:655-60.

54. Jenh CH, Cox MA, Hipkin W, Lu T, Pugliese-Sivo C, Gonsiorek W, et al. Human B cell-attracting chemokine 1 (BCA-1; CXCL13) is an agonist for the human CXCR3 receptor. Cytokine. 2001;15:113-21.

55. Panse J, Friedrichs K, MarX A, Hildebrandt Y, Luetkens T, Barrels K, et al. Chemokine CXCL13 is overexpressed in the tumour tissue and in the peripheral blood of breast cancer patients. Br J Cancer. 2008;99:930-8.

56. Meijer J, Zeelenberg IS, Sipos B, Roos E. The CXCR5 chemokine receptor is expressed by carcinoma cells and promotes growth of colon carcinoma in the liver. Cancer Res. 2006:66:9576-82.

57. Burkle A, Niedermeier M, Schmitt-Graff A, Wierda WG, Keating MJ, Burger JA. Overexpression of the CXCR5 chemokine receptor, and its ligand, CXCL13 in B-cell chronic lymphocytic leukemia. Blood. 2007;110:3316-25.

58. Airoldi I, Cocco C, Morandi F, Prigione I, Pistoia V. CXCR5 may be involved in the attraction of human metastatic neuroblastoma cells to the bone marrow. Cancer Immunol Immunother. 2008:57:541-8.

59. El HC, Sharma PK, Singh R, Johnson PR, Suttles J, Singh S, et al. PI3Kp110-, Src-, FAK-dependent and DOCK2-independent migration and invasion of CXCL13-stimulated prostate cancer cells. Mol Cancer. 2010;9:85.

60. Zeng J, Yang X, Cheng L, Liu R, Lei Y, Dong D, et al. Chemokine CXCL14 is associated with prognosis in patients with colorectal carcinoma after curative resection. J Transl Med. 2013;11:6.

61. Razmkhah M, Jaberipour M, Safaei A, Talei AR, Erfani N, Ghaderi A. Chemokine and chemokine receptors: a comparative study between metastatic and nonmetastatic lymph nodes in breast cancer patients. Eur Cytokine Netw. 2012;23:72-7.

62. Biswas S, Sengupta S, Roy CS, Jana S, Mandal G, Mandal PK, et al. CXCL13CXCR5 co-expression regulates epithelial to mesenchymal transition of breast cancer cells during lymph node metastasis. Breast Cancer Res Treat. 2014;143:265-76

63. Salgado R, Denkert C, Demaria S, Sirtaine N, Klauschen F, Pruneri G, Wienert $\mathrm{S}$, Van den Eynden G, Baehner FL, Penault-Llorca F, et al. The evaluation of tumor-infiltrating lymphocytes (TILs) in breast cancer: recommendations by an International TlLs Working Group 2014. Ann Oncol 2014.

64. Loi S, Michiels S, Salgado R, Sirtaine N, Jose V, Fumagalli D, et al. Tumor infiltrating lymphocytes are prognostic in triple negative breast cancer and predictive for trastuzumab benefit in early breast cancer: results from the FinHER trial. Ann Oncol. 2014:25:1544-50.

65. Loi S, Sirtaine N, Piette F, Salgado R, Viale G, Van Eenoo F, et al. Prognostic and predictive value of tumor-infiltrating lymphocytes in a phase III randomized adjuvant breast cancer trial in node-positive breast cancer comparing the addition of docetaxel to doxorubicin with doxorubicin-based chemotherapy: BIG 02-98. J Clin Oncol. 2013;31:860-7.
66. Denkert C, Loibl S, Noske A, Roller M, Muller BM, Komor M, et al. Tumorassociated lymphocytes as an independent predictor of response to neoadjuvant chemotherapy in breast cancer. J Clin Oncol. 2010;28:105-13.

67. Adams S, Gray RJ, Demaria S, Goldstein L, Perez EA, Shulman LN, et al. Prognostic value of tumor-infiltrating lymphocytes in triple-negative breast cancers from two phase III randomized adjuvant breast cancer trials: ECOG 2197 and ECOG 1199. J Clin Oncol. 2014;32:2959-67.

68. Zamarron BF, Chen W. Dual roles of immune cells and their factors in cancer development and progression. Int J Biol Sci. 2011;7:651-8.

69. Ruffell B, DeNardo DG, Affara NI, Coussens LM. Lymphocytes in cancer development: polarization towards pro-tumor immunity. Cytokine Growth Factor Rev. 2010;21:3-10.

70. Gobert M, Treilleux I, Bendriss-Vermare N, Bachelot T, Goddard-Leon S, Arfi V, Biota C, Doffin AC, Durand I, Olive D, et al. Regulatory T cells recruited through CCL22/CCR4 are selectively activated in lymphoid infiltrates surrounding primary breast tumors and lead to an adverse clinical outcome., vol. 69. pp. 2000-2009; 2009:2000-2009.

71. Razis E, Kalogeras KT, Kotoula V, Eleftheraki AG, Nikitas N, Kronenwett R, et al. Improved outcome of high-risk early HER2 positive breast cancer with high CXCL13-CXCR5 messenger RNA expression. Clin Breast Cancer. 2012:12:183-93.

72. Gu-Trantien C, Loi S, Garaud S, Equeter C, Libin M, de Wind A, et al. CD4(+) follicular helper $\mathrm{T}$ cell infiltration predicts breast cancer survival. J Clin Invest. 2013;123:2873-92.

73. Negus RP, Stamp GW, Relf MG, Burke F, Malik ST, Bernasconi S, et al. The detection and localization of monocyte chemoattractant protein-1 (MCP-1) in human ovarian cancer. J Clin Invest. 1995;95:2391-6.

74. Luboshits G, Shina S, Kaplan O, Engelberg S, Nass D, Lifshitz-Mercer B, et al. Elevated expression of the $\mathrm{CC}$ chemokine regulated on activation, normal $\mathrm{T}$ cell expressed and secreted (RANTES) in advanced breast carcinoma. Cancer Res. 1999:59:4681-7.

75. Saji H, Koike M, Yamori T, Saji S, Seiki M, Matsushima K, et al. Significant correlation of monocyte chemoattractant protein-1 expression with neovascularization and progression of breast carcinoma. Cancer. 2001;92:1085-91.

76. Negus RP, Stamp GW, Hadley J, Balkwill FR. Quantitative assessment of the leukocyte infiltrate in ovarian cancer and its relationship to the expression of C-C chemokines. Am J Pathol. 1997;150:1723-34.

77. Ueno T, Toi M, Saji H, Muta M, Bando H, Kuroi K, et al. Significance of macrophage chemoattractant protein-1 in macrophage recruitment, angiogenesis, and survival in human breast cancer. Clin Cancer Res. 2000;6:3282-9.

78. Bailey C, Negus R, Morris A, Ziprin P, Goldin R, Allavena P, et al. Chemokine expression is associated with the accumulation of tumour associated macrophages (TAMs) and progression in human colorectal cancer. Clin Exp Metastasis. 2007:24:121-30.

\section{Submit your next manuscript to BioMed Central and take full advantage of:}

- Convenient online submission

- Thorough peer review

- No space constraints or color figure charges

- Immediate publication on acceptance

- Inclusion in PubMed, CAS, Scopus and Google Scholar

- Research which is freely available for redistribution 